\title{
Poultry Feed Dispensing System Control: A Case between Fuzzy Logic Controller and PID Controller
}

\author{
J.A. BALA, O.M. OLANIYI, T.A. FOLORUNSO and O.T. ARULOGUN
}

\begin{abstract}
The application of precision agriculture in farming practices results in higher yield and productivity with lower costs. Several works have applied this concept to poultry farming in an attempt to reduce human involvement, stress, fatigue, wastage of poultry feed as well as provided a high return on investment. A number of these systems lack control techniques to improve the system performance. A few works exist that implemented control techniques to improve system response, but different systems were implemented and therefore, a comparison cannot be made. In this paper the performance comparison of the Fuzzy Logic Controller (FLC) and the PID Controller on the Poultry Feed Dispensing System was evaluated in a quest to determine the more efficient and effective controller. The system was modelled and simulated using MATLAB SIMULINK and the performance was evaluated based on the rise time, settling time, overshoot and Integrated Absolute Error (IAE). The results showed that the system implemented with the PID and FLC performed better than the system without a control technique. The PID gave a faster system response than the FLC in the solid feed subsystem with a difference in rise time, settling time and IAE of 9.72 seconds, 11.68 seconds and 4.74 respectively. The FLC performed better in the liquid feed subsystem with a difference in rise time, settling time, overshoot and IAE of 9.22 seconds, 33.07 seconds, $13.92 \%$ and 7.18 respectively. This shows that the PID controller is more suitable in the solid feed subsystem and the FLC is more effective in the liquid feed subsystem.
\end{abstract}

Index Terms-Precision Agriculture, PID Controller, Fuzzy Logic Controller, Poultry, Feed Dispensing.

J.A. BALA, is with the Department of Mechatronics Engineering, Federal University of Technology, Minna, Nigeria, (e-mail: jibril.bala@futminna.edu.ng).

iD https://orcid.org/ 0000-0003-4886-3924

O.M. OLANIYI, is with is with the Department of Computer Engineering, Federal University of Technology, Minna, Nigeria, (e-mail: mikail.olaniyi@futminna.edu.ng).

(iD https://orcid.org/0000-0002-2294-5545

T.A. FOLORUNSO, is with the Department of Mechatronics Engineering, Federal University of Technology, Minna, Nigeria, (e-mail: funso.taliha@futminna.edu.ng).

(D) https://orcid.org/0000-0002-9373-6679

O.T. ARULOGUN, is with the Department of Computer Science and Engineering, Ladoke Akintola University of Technology, Ogbomoso, Nigeria, (e-mail: otarulogun@lautech.edu.ng).

(D) https://orcid.org/0000-0003-0254-4944

Manuscript received March 5, 2019; accepted April 17, 2019.

DOI: $\underline{10.17694 / \text { bajece. } 536026}$

\section{INTRODUCTION}

DRECISION AGRICULTURE is an information and technology based farm management practice. It is mainly used in farm analysis, variability identification and management for optimum sustainability and profitability. It serves as a feasible alternative for land resource protection and productivity [1]. Site specific management (SSM) requires doing the right thing, at the right place and at the right time. Precision Agriculture makes it possible for SSM to be applied to farms using information technology. Precision agriculture uses agricultural practices to alter inputs to produce the desired outputs as well as monitor those outputs [2]. Precision agriculture results in a higher or equal yield with lower costs in production thereby having a positive impact on farm economics and productivity [3].

Due to the increase in the demand for poultry products, there is a need for poultry farmers to meet the demand of their customers. These poultry farmers need to produce poultry birds that meet the high standards of the market within the shortest time possible [4]. The major problem associated with poultry farming especially in developing countries is that the feeding of the poultry birds is done manually which leads to contamination of the feed, wastage, stress and fatigue on the side of the farmers. These pitfalls result in poultry farming being carried out in the tropics at a high cost with a little return on investment [5]. Due to these shortcomings, there is a need to employ the principles of precision agriculture to develop systems that automate the process of poultry feeding.

The Proportional-Integral-Derivative (PID) controller is a feedback control mechanism which is widely used in the control industry. Its high demand is as a result of its control capabilities for a wide range of industrial applications such as DC motors, automotive and flight control. About $95 \%$ of control loops in process control are implemented with a PID controller due to their simplicity in structure and robust performance in a wide range of applications. [6]. Fuzzy logic control is often seen as an alternative to PID control. This is because the use of rules and membership functions in parameterization makes it easier to add logic, non-linearities and additional input signals in control applications. As a result of this, fuzzy logic controllers have recently been widely used in industrial processes due to their simplicity and effectiveness in dealing with both linear and non-linear systems [7].

In order to achieve a system with high performance and robustness, a suitable controller needs to be used. However, the tuning of control parameters to achieve optimum performance is a tedious task. Fuzzy logic blurs the line between control 
engineering and artificial intelligence which makes it a suitable option. However, PID controllers are widely used in control applications due to their efficiency, ease of implementation and robustness [8].

Several works have been carried out in the area of poultry feeding systems. [9] designed a self-propelled poultry feed dispensing system. The system had feed level sensing capabilities and employed a parallel port connection with a computer. However, this system had no control technique implemented, had a limited range due to the parallel port and incurred a high cost of parallel port maintenance. [10] developed a mobile intelligent poultry feeding system with obstacle detection and avoidance. The system dispensed solid feed but had no liquid feed dispensing capabilities. Also, no control technique was employed in the development. [4] developed a mechanical poultry feeder which limited the feed dispensed based on the weight of feed on the trough. The system was not intelligent, had no liquid feed dispensing capabilities and employed no control technique.

The absence of control techniques in [10], [9] and [4] was addressed in [11]. Here, an intelligent poultry liquid feed dispensing system was developed using fuzzy logic. The system also had feed sensing capabilities to limit the time in which the feed was dispensed. However, the system could not dispense solid feed and the fuzzy logic control was designed and limited to feed dispensing and was not designed to improve system response. [12] developed a mobile intelligent poultry feed dispensing system using a PID controller tuned with Genetic Algorithm (GA). The results showed that the system response with the GA based PID controller performed better than the system implemented without a controller. The system however could not dispense solid feed. [5] de veloped a mobile intelligent poultry feed dispensing system using a PID controller tuned with Particle Swarm Optimization (PSO). This system dispensed both solid and liquid feed. The results showed that the PSO based PID system performed better than the system implemented without a control technique.

Due to the shortcomings of the works presented above such as absence of control techniques, undesirable system response, susceptibility to instability and disturbances (such as noise and vibrations), this paper presents a performance evaluation of a poultry feeding system implemented with a Fuzzy Logic Controller (FLC) and a PID controller in a quest to determine the more suitable, effective and efficient control technique in the poultry feed dispensing system. The paper adopts the system model in [5] and was simulated using MATLAB/SIMULINK. The Fuzzy Logic Controller was designed using the Fuzzy Logic Designer toolbox provided by MATLAB while the PID controller was designed and tuned using the PID tuner, also provided by MATLAB. The system performance was evaluated in terms of its system response parameters such as rise time, settling time, overshoot and Integrated Absolute Error (IAE).

The remaining parts of the paper are organized into four sections. Section 2 gives a background on fuzzy logic and PID control. Section 3 gives a description of the system modelling, design and simulation. The results and discussion are presented in section 4 while the conclusion and recommendations for future works are presented in section 5 .

\section{BACKGROUND OF THE STUDY}

\section{A. Proportional-Integral-Derivative Control}

Proportional Integral and Derivative controllers have been around for a very long time, and despite being used in industrial control applications for a while, they are still widely used today. This is due to their simplicity, low cost, robustness and ease of re-tuning [8], [13]. PID controllers calculate the error value based on a measured process variable and the desired set point. The controller attempts to minimize or eliminate the error by adjusting the controller parameters [6].

The PID controller consists of three terms: the proportional term, integral term and the derivative term. These terms depend on the error value between the input and output. The equation of a PID controller can be represented as shown in equation 1 .

$u(t)=K_{p} e(t)+K_{i} \int_{0}^{t} e(t) d t+K_{d} \frac{d}{d t} e(t)$

Where $u(t)$ represents the control signal given as the output of the controller, $\mathrm{K}_{\mathrm{p}}$ represents the proportional gain parameter, $\mathrm{K}_{\mathrm{i}}$ represents the integral gain parameter, $K_{d}$ represents the derivative gain parameter and $\mathrm{e}(\mathrm{t})$ represents the error signal. From equation 1, it can be seen that the output of the controller depends on the values of $K_{p}, K_{i}$ and $K_{d}$. Therefore, changes in the values of these terms produce a change in the value of the final output.

The proportional gain increases the speed of the system as the output is proportional to the error value. The integral gain reduces the steady state error of the system while the derivative gain improves the transient response of the system by reducing the overshoot [13]. The proportional term depends on the present error, the integral term depends on past error values while the derivative term predicts future error values. These parameters are adjusted to obtain a control signal that will improve the system performance by reducing the rise and settling times as well as reducing the steady state error and overshoot [6]. The transfer function of a PID controller is represented by equation 2 .

$K(S)=K_{p}+\frac{K_{i}}{s}+K_{d} s$

The selection of $\mathrm{K}_{\mathrm{p}}, \mathrm{K}_{\mathrm{i}}$ and $\mathrm{K}_{\mathrm{d}}$ are is called tuning of the PID controller. There are two major categories of tuning which are the classical method and the computational or optimization method. The classical method is a traditional method of PID control which makes assumptions regarding the plant and attempts to tune the parameters analytically. This method is computationally fast but not always accurate as assumptions are made. Examples are the Ziegler-Nichols method and CohenCoon Method. The computational or optimization methods aim to tune the control parameters by optimizing a cost function by the use of artificial intelligent techniques, optimization algorithms or software packages. Examples include genetic algorithm, artificial neural networks and particle swarm optimization[13]. In this study, the PID tuner provided by MATLAB was used in tuning the PID controller. It is a custom PID tuning algorithm developed by Mathworks ${ }^{\odot}$ which attempts to tune the controller gains to improve the system performance. 


\section{B. Fuzzy Logic}

Fuzzy Logic was introduced by Lofti Zadeh at the University of California, Berkley, in the 1960s to model the uncertainty of natural language [14]. Fuzzy Logic is a method that provides a definite solution from imprecise and vague information. It achieves that by using a set of mathematical principles used to represent knowledge based on degrees of membership [15]. Fuzzy Logic has widespread applications in control engineering, signal processing, artificial intelligence.

Fuzzy Logic control was first used in the controller design for the steam engine in 1974. Fuzzy Logic can model human experience accurately and provides an efficient way to implement intelligent control in industrial applications [16]. Fuzzy logic implementation in control engineering is based on designing a self-adapting control system which maintains a particular closed loop performance by learning about changes that might affect the process behavior[14].

The fuzzy logic approach is made up of five steps:

1. Define all input and output variables.

2. Define the subset interval.

3. Choose the membership function.

4. Define the IF-THEN rules.

5. Perform calculations and adjust the rules [12].

Fuzzy logic is widely used due to its flexibility, ease of understanding, tolerance of imprecise data and its ability to be blended with other conventional control techniques [14]. Figure 1 shows a basic fuzzy logic system.

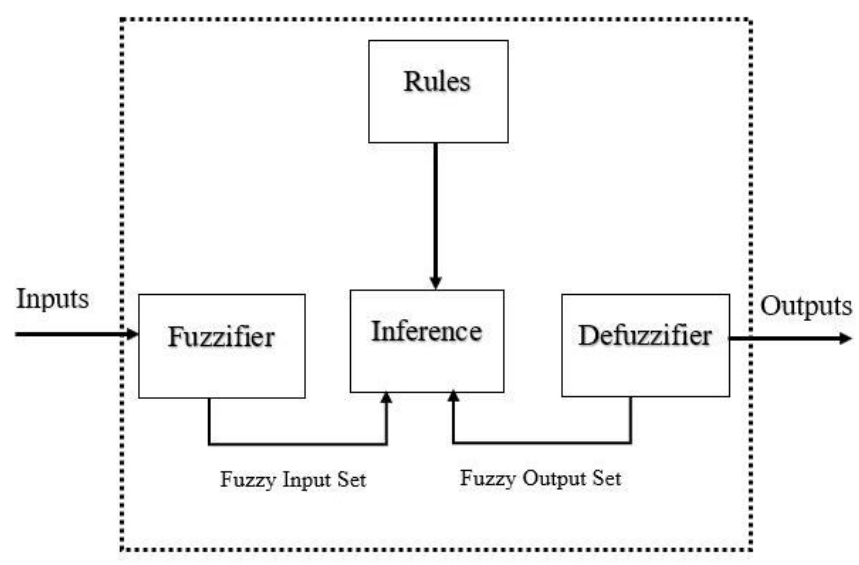

Figure 1: Fuzzy Logic System

\section{METHODLOGY AND CONTROLLER DESIGN}

\section{A. System Description}

The mobile intelligent poultry feed dispensing system developed in [5] serves as the baseline for this work. This paper implements the models of the two subsystems of the poultry feeding system using a PID controller and also a fuzzy logic controller. The system consists of a power supply unit, an embedded unit, a solid and liquid feed dispensing unit as well as a mechanical unit. The power supply unit comprises of a $12 \mathrm{~V}$ DC battery which powers the entire system. The embedded unit consists of an Arduino mega microcontroller which is connected to the feed dispensing units and the mechanical unit. The feed dispensing units consist of a DC motor and a DC pump to dispense solid and liquid feed from the trough to the feeder/drinker. The mechanical unit consists of the wheels which enables the system to move within a deep litter poultry farm.

Figure 2 shows a diagram of the developed mobile intelligent poultry feed dispensing system. The system is modelled in terms of a DC motor and the flow rate of the liquid feed system. The system is modelled from first principle and presented in equations (3) and (4) [5]. The system iss simulated using the Fuzzy Logic Controller and PID Controller in MATLABSIMULINK (R2018b version) and the performance is evaluated based on the system response parameters (rise time, settling time and overshoot).

$$
\begin{aligned}
& G_{\text {liquid }}(s)=\frac{8.5}{S+0.07142} \\
& G_{\text {solid }}(s)=\frac{3.475}{0.00374^{2}+0.51599 S+12.33831}
\end{aligned}
$$

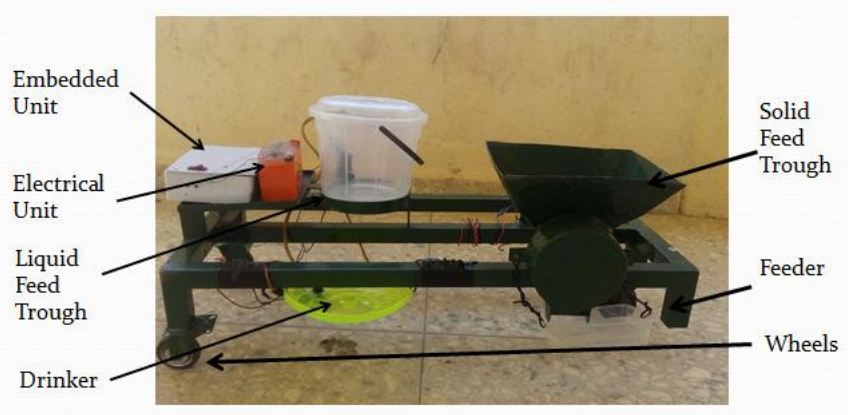

Figure 2: Mobile Intelligent Poultry Feed Dispensing System [5]

\section{B. Fuzzy Logic Control Development}

\section{I.Fuzzy Inference System (FIS)}

The Fuzzy Inference System (FIS) is designed using the fuzzy logic toolbox provided by MATLAB. The Mamdani FIS is used in this study due to its widespread acceptance, intuitiveness and suitability for human inputs. The FIS comprised of two inputs (error and change in error) and one output (change in control signal). Defuzzification is achieved using the centroid technique which evaluates the area under a curve. This converts the fuzzy outputs to a crisp output. The output (change in error) is then integrated to provide the final control signal.

\section{II.Membership Functions}

The triangular membership function (MF) is implemented for all the inputs and the output due to its simplicity, wide use and ease of implementation. The input variables are error and change in error (or error variation). The output variable is the change in control signal. All the variables (error, change in error and change in control signal) have a range of -2 to 2 consisting of three MFs. The MFs were Negative (neg), Zero (zer) and 
Positive (pos) with values of $[-2,-1,0],[-1,0,1]$ and $[0,1,2]$ respectively. Figures 3, 4 and 5 show the input and output variables with the corresponding membership functions.

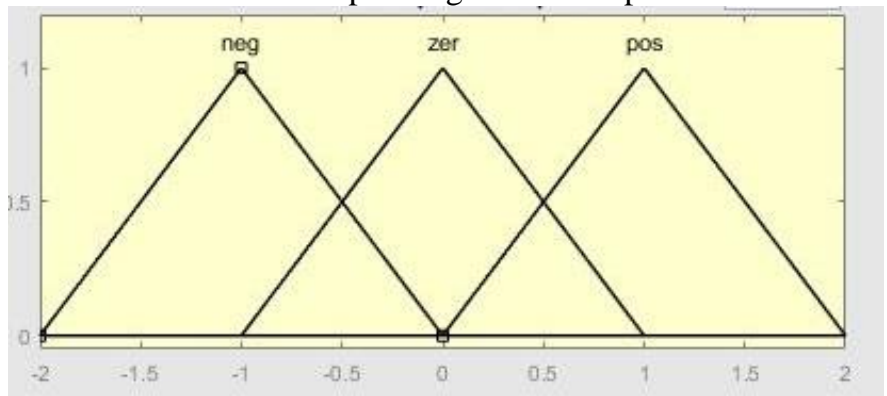

Figure 3: Membership Function for Error Input

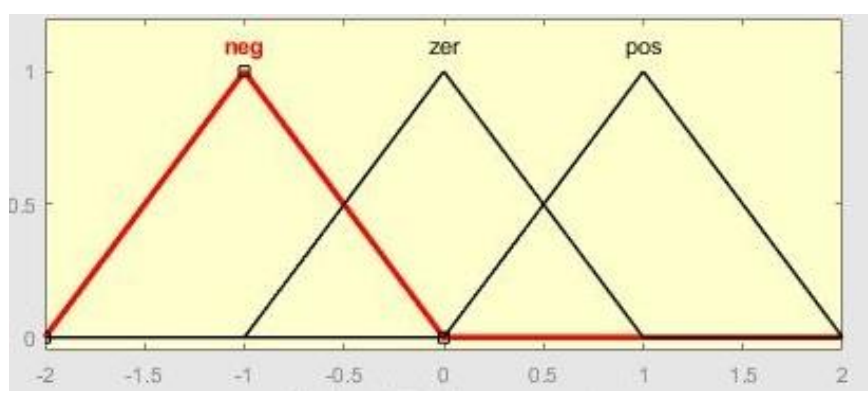

Figure 4: Membership Function for Change in Error Input

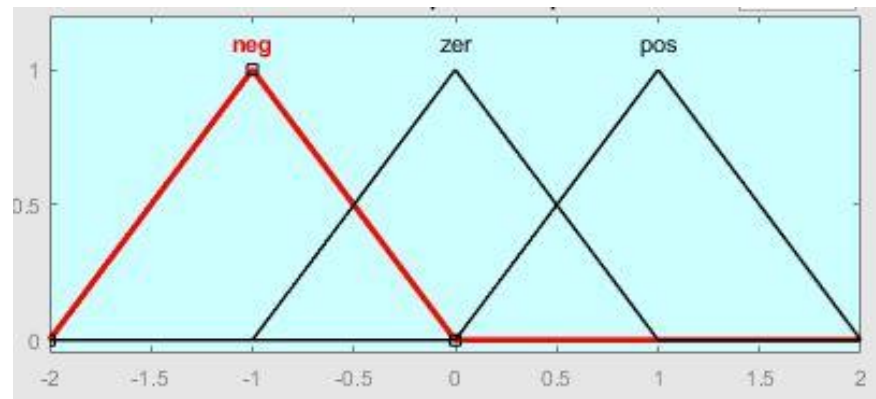

Figure 5: Membership Function for Change in Control Output

\section{III.Fuzzy Rules}

The fuzzy rules are designed based on the following considerations:

i. If the error and change in error is zero, maintain the current output.

ii. If the error is not zero but approaching zero, maintain current control output.

iii. If the error is not zero and growing, change the control output based on the magnitude of the error.

The fuzzy rules are implemented based on the considerations above and the designed fuzzy rules are listed below. Figures 6 and 7 show the rule viewer and the surface viewer which provide a graphical representation of the implemented fuzzy rules.

1. If (error is neg) and (change_in_error is neg) then (change_in_control is neg)

2. If (error is neg) and (change_in_error is zer) then (change_in_control is neg)
3. If (error is neg) and (change_in_error is pos) then (change_in_control is zer)

4. If (error is zer) and (change_in_error is neg) then (change_in_control is neg)

5. If (error is zer) and (change_in_error is zer) then (change_in_control is zer)

6. If (error is zer) and (change_in_error is pos) then (change_in_control is pos)

7. If (error is pos) and (change_in_error is neg) then (change_in_control is zer)

8. If (error is pos) and (change_in_error is zer) then (change_in_control is pos)

9. If (error is pos) and (change_in_error is pos) then (change_in_control is pos)
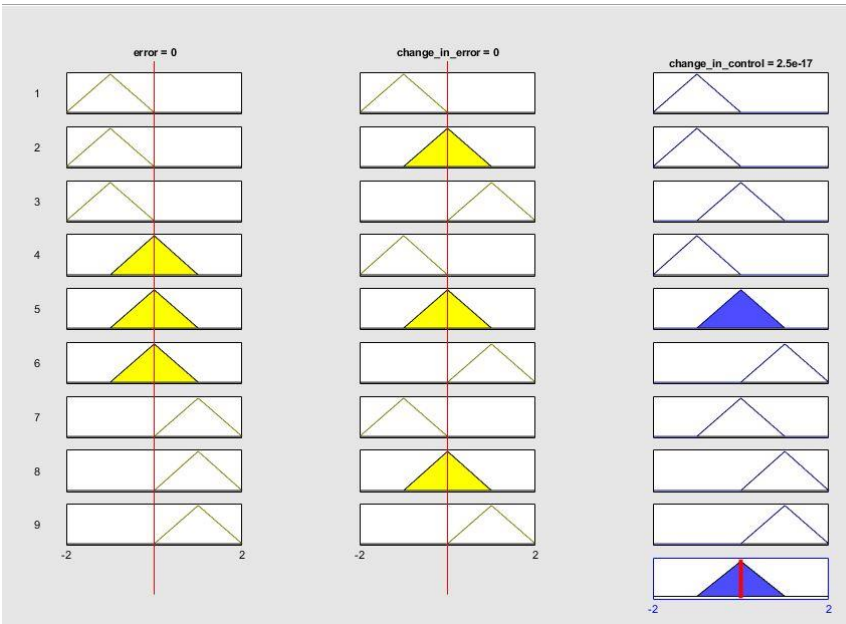

Figure 6: Fuzzy Logic Rules (Rule Viewer)

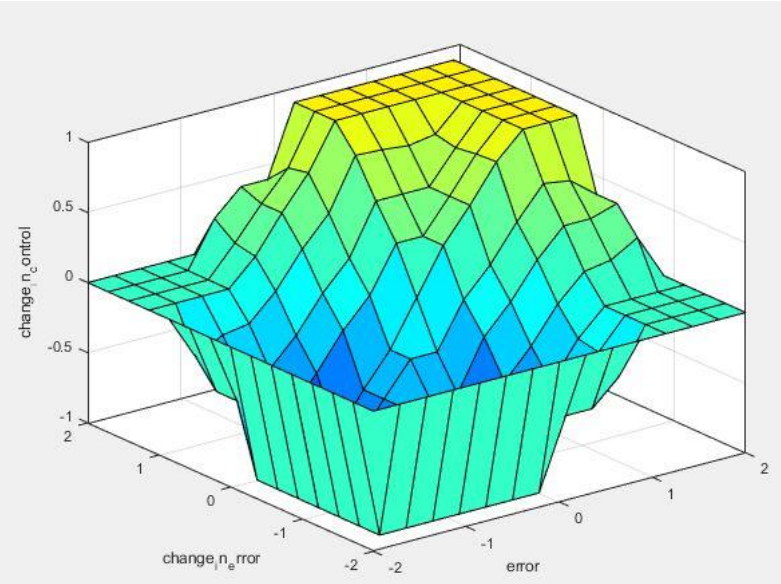

Figure 7: Fuzzy Logic Rules (Surface Viewer)

\section{PID Controller Development}

A closed loop control technique is used in the design. The PID controller is tuned using the PID tuner provided by the MATLAB software. The system is connected in series with a PID controller and a step input is fed into the system. From equations (3) and (4), it can be seen that the different subsystems of the poultry feeding system (solid and liquid) 
have different transfer functions and therefore the PID controller design will vary in both cases. In the case of the solid feed subsystem, the proportional, integral and derivative gains are obtained as $7.0678,271.2664$ and 0.03372 respectively.

On the other hand, the liquid feed subsystem is a first order system and therefore, a PI controller is used by setting the derivative gain to 0 . This is because the derivative term has no significant effect on first order systems and increases the system complexity without significantly improving the performance. The proportional gain is obtained as 0.0088 and the integral gain is obtained as 0.0019 .

The SIMULINK block diagram of the solid and liquid subsystems implemented with both the Fuzzy Logic Controller and PID controller are shown in figures 8 and 9. The outputs of both systems are connected to a single scope to visualize the varying effects of the different controllers on the system.

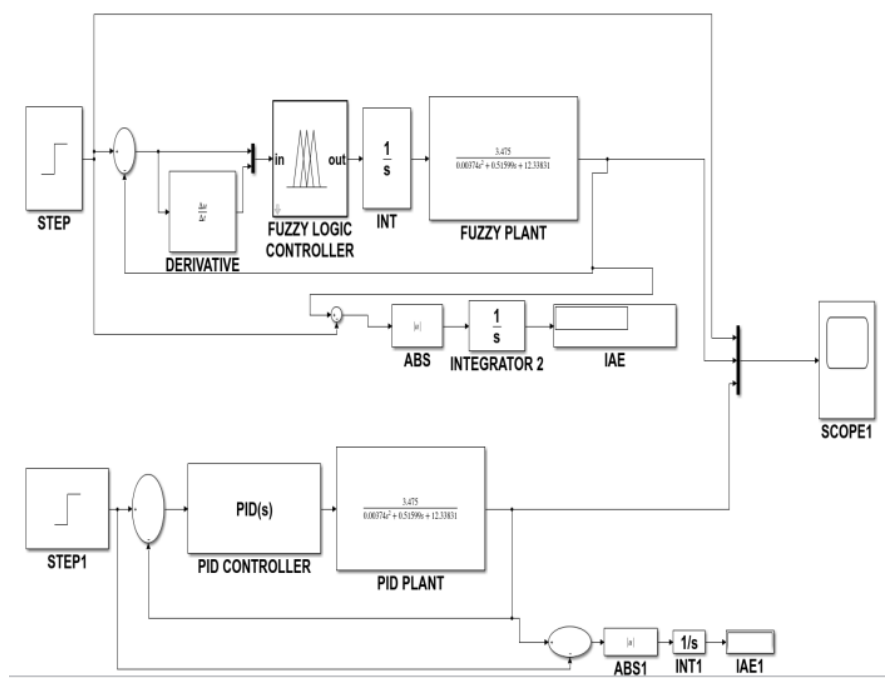

Figure 8: SIMULINK model of the solid feed subsystem with FLC and PID controller

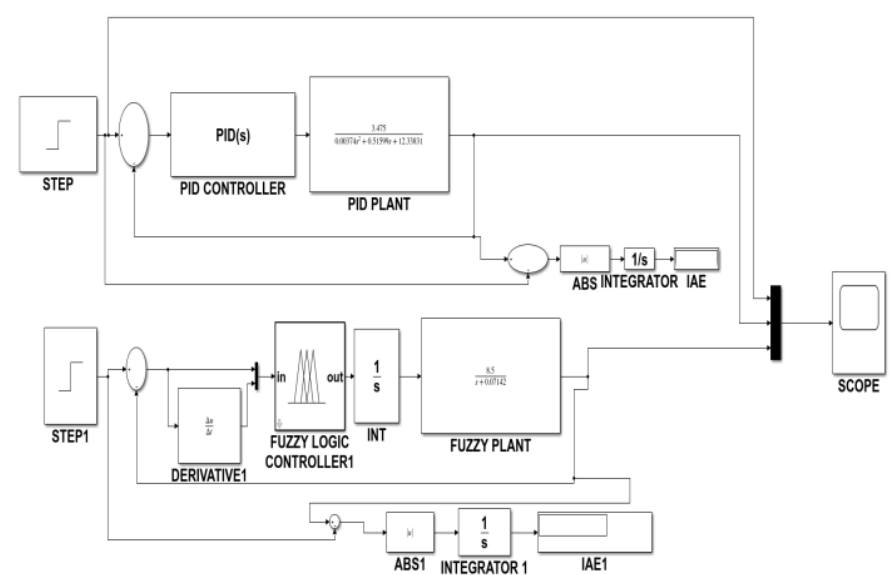

Figure 9: SIMULINK model of the liquid feed subsystem with FLC and PID controller

\section{RESULTS AND DISCUSSION}

The system models are simulated using MATLAB/SIMULINK (R2018b version). The performance of each system is evaluated based on the rise time, settling time, overshoot and the
Integrated Absolute Error (IAE). The subsystems are modelled separately due to the difference in order and controller design.

\section{A. Solid Feed Subsystem}

The solid feed subsystem is connected in series with the fuzzy logic controller as well as the PID controller. Figure 10 shows the response of the solid feed subsystem.

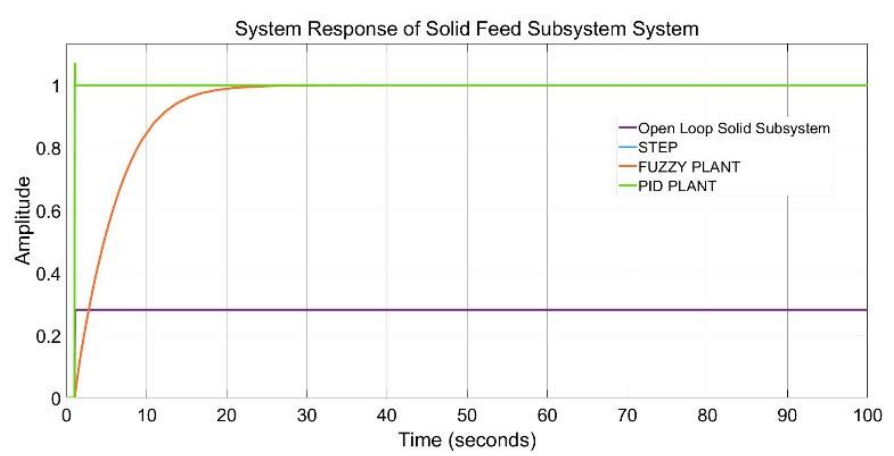

Figure 10: System Response of Solid Feed Subsystem

As shown in figure 10, the open loop system (without a controller) has a rise time of 0.076 seconds, a settling time of 0.100 seconds and an overshoot of $0.505 \%$. However, the system has an IAE of 71.13 which is too high and unfavourable. In addition, the system's output never reaches the reference input as it is less than $30 \%$ of the input. This indicates that without a control mechanism, the system response is quite poor due to the large error value. The PID controlled system has a rise time of 0.0281 seconds, a settling time of 0.0879 seconds and an overshoot of $6.989 \%$. The system has an IAE of 0.0195 . On the other hand, the fuzzy logic controlled system has a higher rise time, settling time and IAE of 9.748 seconds, 11.769 seconds and 4.759 respectively. However, the overshoot is much lower than that of the PID controlled system with a value of $0.505 \%$.

\section{B. Liquid Feed Subsystem}

The liquid feed subsystem is connected in series with the fuzzy logic controller as well as the PID controller, as in the case of the solid feed subsystem. Figure 11 shows the response of the liquid feed subsystem.

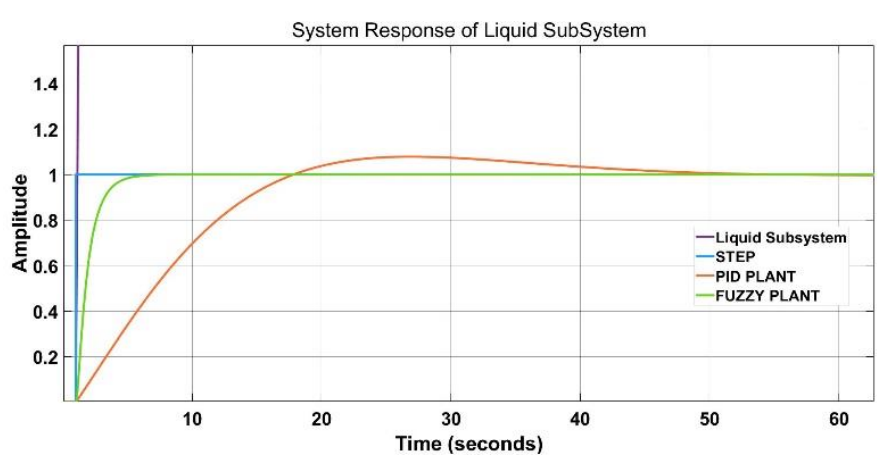

Figure 11: System Response of Liquid Subsystem

From figure 11, it can be seen that the open loop system (without a controller) has a rise time of 30.086 seconds, a settling time of 42.156 seconds and an overshoot of $0.501 \%$. 
However, the system has an IAE of 10020 which is extremely high. In addition, the system's output is about 120 times the reference input. This indicates that without a control mechanism, the system response is very unfavourable. The PID controlled system has a rise time of 11.209 seconds, a settling time of 35.906 seconds and an overshoot of $14.368 \%$. The system has an IAE of 8.213. On the other hand, the fuzzy logic controlled system has a lower rise time, settling time and IAE of 1.990 seconds, 2.838 seconds and 1.033 respectively. The overshoot is also much lower than that of the PID controlled system with a value of $0.446 \%$. Table 1 shows a summary of the results obtained from all the subsystems.

Table 1: Summary of System Response Results

\begin{tabular}{lllll}
\hline $\begin{array}{l}\text { System/ } \\
\text { System } \\
\text { Response } \\
\text { Parameter }\end{array}$ & $\begin{array}{l}\text { Rise } \\
\text { Time } \\
\text { (seconds) }\end{array}$ & $\begin{array}{l}\text { Settling } \\
\text { Time } \\
\text { (seconds) }\end{array}$ & $\begin{array}{l}\text { Overshoot } \\
(\%)\end{array}$ & IAE \\
\hline $\begin{array}{l}\text { No } \\
\begin{array}{l}\text { Controller } \\
\text { (Solid) }\end{array}\end{array}$ & 0.076 & 0.101 & 0.505 & 71.13 \\
\hline $\begin{array}{l}\text { No } \\
\text { Controller } \\
\text { (Liquid) }\end{array}$ & 30.086 & 42.156 & 0.501 & 1.002 \\
\hline $\begin{array}{l}\text { Solid Feed } \\
\text { Subsystem } \\
\text { (PID) }\end{array}$ & 0.028 & 0.088 & 6.989 & 0.019 \\
\hline $\begin{array}{l}\text { Solid Feed } \\
\text { Subsystem } \\
\text { (Fuzzy) }\end{array}$ & 9.748 & 11.769 & 0.505 & 4.759 \\
\hline $\begin{array}{l}\text { Liquid } \\
\begin{array}{l}\text { Feed } \\
\text { Subsystem }\end{array}\end{array}$ & 11.209 & 35.906 & 14.368 & 8.213 \\
(PID) & & & & \\
\hline $\begin{array}{l}\text { Liquid } \\
\text { Feed }\end{array}$ & 1.99 & 2.838 & 0.446 & 1.033 \\
$\begin{array}{l}\text { Subsystem } \\
\text { (Fuzzy) }\end{array}$ & & & & \\
\hline
\end{tabular}

From Table1, it can be seen that without any control mechanism, both subsystems gave a poor performance. In the case of the solid subsystem, the output never reaches the reference input while in the case of the liquid subsystem, the output is much larger than the reference input. In addition, the IAE is large in both subsystems.

In the case of the solid feed subsystem, the PID controller gives a faster response than the Fuzzy Logic Controller (FLC) as the rise time and settling time are lower than the FLC. The IAE is also lower than the FLC. However, the overshoot of the PID is higher than the FLC. This implies that in the case of the solid feed subsystem, the PID provides a faster response and more accurate response than the FLC but with a drawback of overshooting. In the liquid subsystem, the PID controller has higher rise time, settling time, overshoot and IAE than the FLC. The FLC gives a faster and more accurate response than the PID. This implies that the FLC performs better than the PID in the case of the liquid feed subsystem.

\section{CONCLUSION AND RECOMMENDATIONS}

The poultry feed dispensing system was simulated with a fuzzy logic controller and a PID controller. The system response was evaluated based on its rise time, settling time, overshoot and IAE. From the results obtained and the comparisons made, it can be seen that both the PID controller and the fuzzy logic controller give a better performance than the system implemented without a controller. However, the PID controller gives a faster and more accurate response than the FLC in the solid feed subsystem, although the overshoot is higher in the PID controller. The FLC gives a better performance in the liquid feed subsystem in all the system response parameters evaluated.

Future works can attempt integrating multiple control techniques such as Fuzzy-PID and Neuro-Fuzzy control techniques.

\section{REFERENCES}

S. Banu, "Precision Agriculture: Tomorrow's Technology for Today's Farmer," J. Food Process. Technol., vol. 06, no. 08, pp. 813, 2015.

R. Bongiovanni and J. Lowenberg-Deboer, "Precision Agriculture and Sustainability," Precis. Agric., vol. 5, pp. 359-387, 2004.

A. Balafoutis et al., "Precision agriculture technologies positively contributing to ghg emissions mitigation, farm productivity and economics," Sustain., vol. 9, no. 8, pp. 1-28, 2017.

V. I. Umogbai, "Development of a Mechanical Family Poultry Feeder," J. Emerg. Trends Eng. Appl. Sci., vol. 4, no. 6, pp. 837-846, 2013.

O. M. Olaniyi, T. A. Folorunso, K. J.G., and J. A. Bala, "A Mobile Intelligent Poultry Feed Dispensing System Using Particle Swarm Optimized PID Control Technique," in Proceedings of ISTEAMS Multidisciplinary Cross Border Conference, University of Professional Studies, Accra, Ghana, 2016, pp. 185-194.

P. Mohindru, G. Sharma, and P. Pooja, "Simulation Performance of PID and Fuzzy Logic Controller for Higher Order System," Coтmun. Appl. Electron., vol. 1, no. 7, pp. 31-35, 2015.

E. Yesil, M. Guzelkaya, and I. Eksin, "Fuzzy PID controllers: An overview.," in The 3rd Triennial ETAI International Conference on Applied Automatic Systems, At Ohrid, Macedonia, 2003.

V. Kumar, B. Nakra, and A. Mittal, "A review of classical and fuzzy PID controllers," Int. J. Intell. Control Syst., vol. 16, no. 3, pp. 170181, 2011.

B. Omosebi, "Development of a self-propelled poultry feed dispenser with Feed level detector," Ladoke Akintola University of Technology, Nigeria, 2006.

O. T. Arulogun, O. M. Olaniyi, A. O. Oke, and D. O. Fenwa, "Development of Mobile Intelligent Poultry Feed Dispensing System," Medwell J. Eng. Appl. Sci., vol. 5, no. 3, pp. 229-233, 2010.

O. M. Olaniyi, O. F. Salami, O. O. Adewumi, and O. S. Ajibola, "Design of an Intelligent Poultry Feed and Water Dispensing System Using Fuzzy Logic Control Technique," Control Theory Informatics, vol. 4, no. 9, pp. 61-72, 2014.

2] A. Adejumo, "Design and Development of a Mobile Intelligent Poultry Liquid Feed Dispensing System using GA Tuned PID Control Technique," Federal University of Technology, Minna, Nigeria, 2015.

[13] H. O. Bansal, R. Sharma, and P. R. Shreeraman, "PID Controller Tuning Techniques : A Review," J. Control Eng. Technol., vol. 2, no. 
4, pp. 168-176, 2012.

B. Singh and A. K. Mishra, "Fuzzy Logic Control System and its Applications," Int. Res. J. Eng. Technol., vol. 2, no. 8, pp. 742-746, 2015.

[15] A. S. Omar, M. Waweru, and R. Rimiru, "Application of Fuzzy Logic in Qualitative Performance Measurement of Supply Chain Management," Int. J. Inf. Commun. Technol. Res., vol. 5, no. 6, 2015.

[16] Y. Luo et al., "Fuzzy-Logic-Based Control, Filtering, and Fault Detection for Networked Systems : A Survey," Math. Probl. Eng., vol. 2015, 2015.

\section{BIOGRAPHIES}

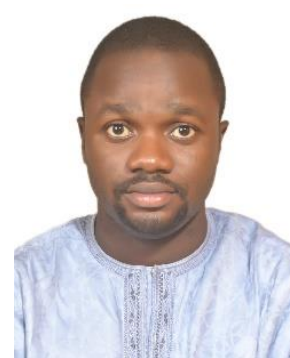

Jibril Abdullahi Bala is a Graduate Assistant with the Department of Mechatronics Engineering, Federal University of Technology, Minna, Nigeria. He obtained his Bachelor's degree in Computer Engineering from Federal University of Technology, Minna, Nigeria. His area of interests are Control, Artificial Intelligence and

Embedded Systems.

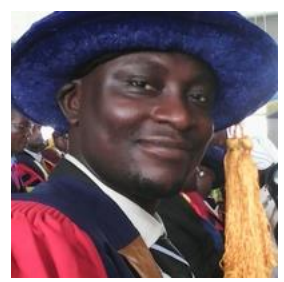

Olayemi Mikail Olaniyi is a Senior Lecturer in the Department of Computer Engineering at Federal University of Technology, Minna, Niger State, Nigeria. He obtained his B.Tech. and M.Sc. in Computer Engineering and Electronic and Computer Engineering respectively. He had his Ph.D. in Computer Security from Ladoke Akintola University of Technology, Ogbomosho, Oyo State, Nigeria. He has published in reputable journals and learned conferences. His areas of research include Computer Security, Intelligent/Embedded Systems design and Applied Medical Informatics.

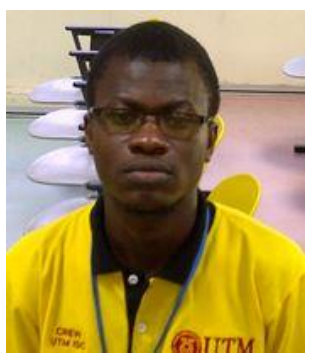

Folorunso Taliha Abiodun is a Lecturer in the Department of Mechatronics Engineering Federal University of Technology Minna. He completed in Bachelor's degree of Engineering in Electrical/Electronics Engineering at the Prestigious Ladoke Akintola University of Technology Ogbomoso Nigeria and proceeded to the famous Universiti Teknologi Malaysia for his Master's Degree in Mechatronics and Automatic Control Engineering. He has published in reputable journals and learned conferences. His areas of research include: Control system, systems identification and estimation, Embedded Systems and Precision Agriculture.

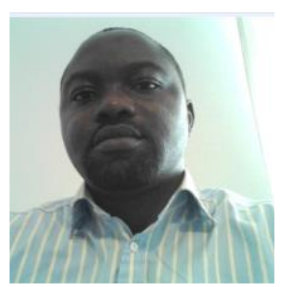

Oladiran T Arulogun is an Associate Professor in the Department of Computer Science and Engineering, Ladoke Akintola University of Technology, Ogbomoso, Nigeria. He was a visiting Research scholar at Hasso-Plattner Institute, Potsdam, Germany in 2012. He has published in reputable journals and learned conferences. His research interests include Networks Security, Wireless Sensor Network, Intelligent Systems and its applications. 